\title{
FEM modelling and analysis of reinforced concrete section with lightweight blocks infill
}

\author{
Ade Sri Wahyuni, Vanissorn Vimonsatit \& Hamid Nikraz \\ Department of Civil Engineering, Curtin University of Technology, Perth, Australia
}

\begin{abstract}
In an attempt to reduce the self weight of reinforced concrete structures, a new development of lightweight sandwich reinforced concrete (LSRC) section has been proposed as an alternative option to solid section. LSRC section is a reinforced concrete section which contains lightweight blocks as infill material. An experimental investigation into the strength of LSRC beams has shown promising results under flexural tests. To ensure the serviceability of LSRC members under service load, it is necessary to accurately predict the cracking and deflection of this section. This paper will focus on analysing the behaviour of the tested beam specimens after cracking occurs. ANSYS 12.1 was employed to study the crack propagation of LSRC beams under bending. The numerical model shows the crack in the area of AAC blocks which associates with the brittle failure of LSRC beams. The crack propagation of the beams analysed by ANSYS agrees well with the results from the experimental investigation.
\end{abstract}

Keywords: lightweight concrete; reinforced concrete; composite section; sandwich section; ANSYS

\section{INTRODUCTION}

A newly developed lightweight reinforced concrete (LSRC) section has been experimentally investigated (Vimonsatit et al. 2010). The section is made up of a reinforced concrete with lightweight block infill. LSRC section can be used either as beams or slabs. Figure 1 shows the construction of LSRC beams. The developed LSRC members are suitable for large span construction due to the weight saving benefits and ease of construction. This paper focuses on analysing the behaviour of the tested beam specimens after cracking occurs.

Finite element method (FEM) is a powerful tool commonly used for analysing a broad range of engineering problems in different environments. FEM
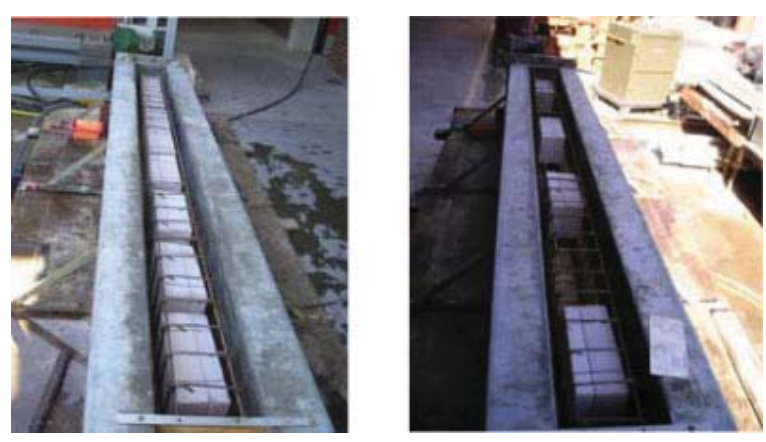

Figure 1. Construction of LSRC beams. is employed extensively in the analysis of solids and structures and of heat transfer and fluids. A nonlinear FEM computer program ANSYS has been widely used for academic research as well for solving practical problems.

Buyukkaragoz (2010) used ANSYS to study on the subject of strengthening the weaker part of the beam by bonding it with prefabricated reinforced concrete plate. Single load was applied in the middle of the beam. solid65 and link8 were employed to model the reinforced concrete with discrete reinforcement, while solid46 was used for modeling the epoxy which is used to bond the prefabricated plate to the beam. The result from experiment in the laboratory is quite similar to the finite element finding.

Barbosa and Riberio (1998) used ANSYS to compare the nonlinear modeling of reinforced concrete members with discrete and smeared reinforcement. Two different modeling were made for the same beam. Concrete was defined with solid65. In the first model, link8 bar was used as discrete reinforcement element. In the second model, steel reinforcement was modeled as smeared concrete element, defined according to the volumetric proportions of steel and concrete. Each model was analyzed four times according to four different material models. Based on their analysis, the results of the load-displacement curves were very similar for both discrete and smeared reinforcement. The differences exhibited at the load greater than the service load when the effects of material modeling led to 
the difference in the nonlinear behavior and ultimate load capacity.

Ibrahim and Mubarak (2009) used ANSYS to predict the ultimate load and maximum deflection at mid-span of continuous concrete beams, which were pre-stressed using external tendons. This model accounts for the influence of the second-order effects in externally pre-stressed members. The results predicted by the model were in good agreement with experimental data.

Padmarajaiah and Ramaswamy (2001) investigated the prestressed concrete with fiber reinforcement. They used COMBIN14 (spring) elements to model the interface behavior between the concrete and reinforcement. They found that the crack pattern predicted by ANSYS is in close agreement with the experimental results. Dahmani et al (2010), found that discrete reinforcement approach give better results than the smeared one. Kachlakev et al., (2001) studied beams externally strengthened with reinforced plastic carbon fiber (CFRC) with no stirrups being used in the experiment.

In the present study, ANSYS version 12.1 is employed for the numerically modeling of the LSRC beam because of its proven useful 3-D reinforced concrete element provided in the element library. In the following sections, beam details used in the experiment will be briefly described, followed by the description of the developed finite element modeling of concrete and steel reinforcement. The crack development of beams will be presented to compare with the experimental results.

\section{FINITE ELEMENT MODELLING}

The concrete was modeled with solid65, which has eight nodes with three degrees of freedom at each node, i.e., translation in the nodal $\mathrm{x}, \mathrm{y}$, and $\mathrm{z}$ directions. The element is capable of plastic deformation, cracking in three orthogonal directions, and crushing.

A link8 element was used to model the steel reinforcement. This element is also capable of plastic deformation. Two nodes are required for this element which has three degree of freedom, as in the case of the concrete element. Discrete method was applied in the modelling of the reinforcement and stirrups used in the tested specimen. The two elements were connecting at the adjacent nodes of the concrete solid element, such that the two materials shared the same nodes. By taking advantage of the symmetry of the beam layout, only half of the beam in longitudinal direction has been modeled in the finite element analysis.

\subsection{Concrete}

For concrete, ANSYS requires an input data for material properties, which are Elastic modulus $\left(E_{c}\right)$, ultimate uniaxial compressive strength $\left(f_{c}^{\prime}\right)$, ultimate uniaxial tensile strength (modulus of rupture, $f_{r}$ ),
Poisson's ratio $(\nu)$, shear transfer coefficient $\left(\beta_{t}\right)$. The modulus of elasticity of concrete was $32000 \mathrm{MPa}$ which was determined in accordance with AS 1012.17 (1997). Poisson's ratio for concrete was assumed to be 0.2 for all the beams.

The shear transfer coefficient, $\beta_{t}$, represents the conditions of the crack face. The value of $\beta_{t}$, ranges from 0 to 1 with 0 representing a smooth crack (complete loss of shear transfer) and 1 representing a rough crack (i.e., no loss of shear transfer) as described in ANSYS. The value of $\beta_{t}$ specified in this study is 0.4 .

The numerical expressions by Desayi and Krisnan (1964), Eqs. (1) and (2), were used along with Eq. (3) (Gere and Timoshenko 1997) to construct the multilinear isotropic stress-strain curve for concrete in this study.

$$
\begin{aligned}
& f=\frac{E_{c} \varepsilon}{1+\left(\frac{\varepsilon}{\varepsilon_{0}}\right)^{2}} \\
& \varepsilon_{0}=\frac{2 f_{c}^{\prime}}{E_{c}} \\
& E=\frac{f}{\varepsilon}
\end{aligned}
$$

where:

$f=$ stress at any strain $\varepsilon$

$\varepsilon=$ strain at stress $\mathrm{f}$

$\varepsilon_{o}=$ strain at the ultimate compressive strength $f_{c}^{\prime}$

The concrete used was grade 40 , having the compressive strength of $43.3 \mathrm{MPa}$ at 28 days. The strength value of AAC blocks used in the model was $3.5 \mathrm{MPa}$. The compressive stress at 0.3 of the compressive strength was used as the first point of the multi-linear stress-strain curve.

The crushing capability of the concrete was turned off to avoid any premature failure (Barbosa and Riberio 1998).

\subsection{Steel reinforcement}

All beams were provided with top and bottom longitudinal bars, N20 bars were used as the bottom steel in all beams with tensile strength at yield was $560 \mathrm{MPa}$ while the yield strength of R-bars which was used as the top bar and the stirrup was $300 \mathrm{MPa}$.

The steel for the finite element models was assumed to be an elastic-perfectly plastic material and identical in tension and compression. Poisson ratio of 0.3 was used for the steel. Elastic modulus, $E_{s}=200,000 \mathrm{MPa}$

\section{LOAD DEFLECTION RELATION OF BEAMS FAIL IN FLEXURE}

The load deflection characteristics from the Finite Element Analysis (SB1F, LB1F, LB2F) are plotted to compare with the flexural test results in Figure 2. All 


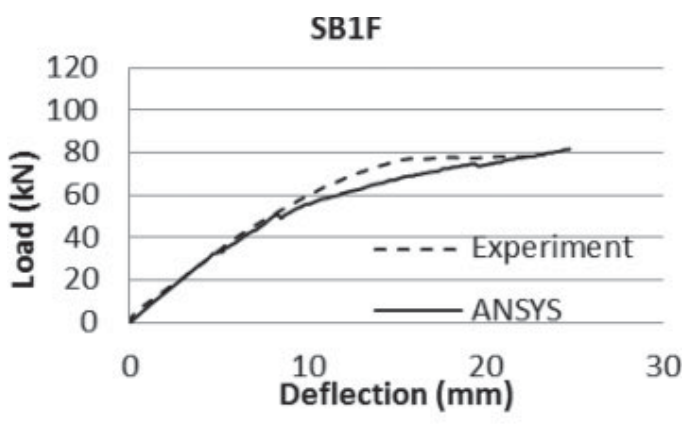

LB1F
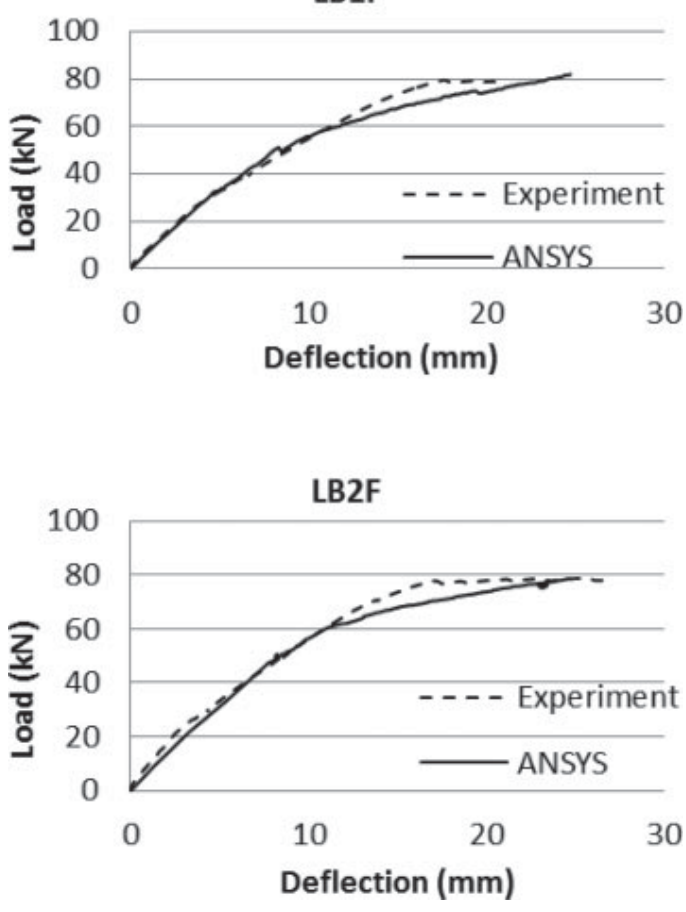

Figure 2. Load-deflection relation of beams.

results show similar trend of the linear and nonlinear behaviour of the beam. In the linear range, the load-deflection relation from the finite element analysis agrees well with the experimental results. After the first cracking, the finite element still follow the same stiffness as in the experimental one. However after the second cracking occurs in the finite element analysis the loss of stiffness can be clearly seen until it fail at same load as the experimental one. Based on these results, the concrete replacement by AAC blocks, as tested on LB1F and LB2F, has virtually no effect on the flexural strength of the section, which is as expected.

\section{CRACK PROPAGATION OF SOLID AND LSRC BEAMS}

During the experiment, The specimens was carefully observed for crack and its propagation. Figures 3, 4 , and 5 show the crack pattern obtained at failure for beams SB1F, LB1F and LB2F. The experimental results are compared with the crack pattern obtained

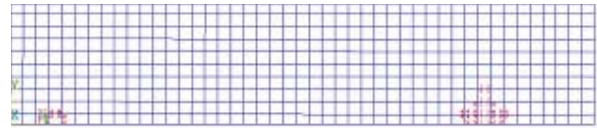

$32.9 \mathrm{kN}$

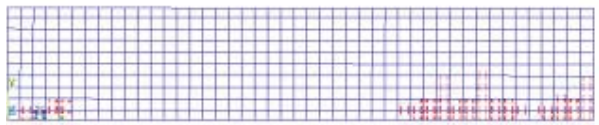

$50.6 \mathrm{kN}$

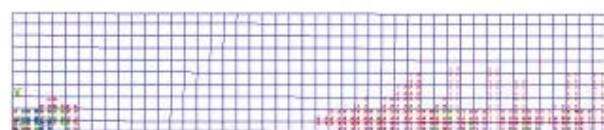

$73.5 \mathrm{kN}$

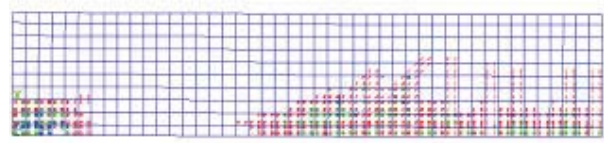

$89.9 \mathrm{kN}$

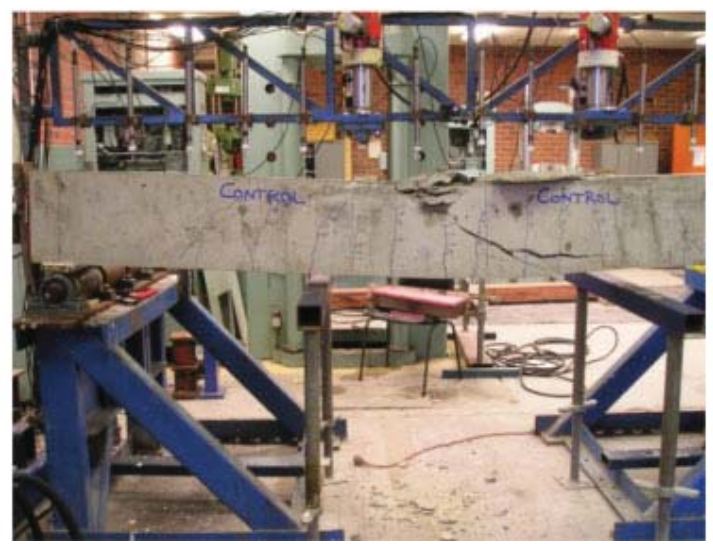

Figure 3. Crack propagation SB1F.

from ANSYS. In this figure, small dash lines indicates the crack location at the certain load level

\subsection{Control beam (SB1F)}

In the control beam which failed in flexure, the crack started to occur underneath the loading point at $32.9 \mathrm{kN}$ load level. This flexural crack expanded as the load level increased. Figure 3 shows the crack propagation until load level $89.9 \mathrm{kN}$. However, the crushing capability of ANSYS was turned off, so the crushing related crack at the top of the beam could not be observed.

\subsection{Beam with maximum amount of AAC blocks (LB1F)}

The crack pattern of the beam contains maximum amount of AAC blocks is illustrated in Figure 4. Beam LB1F has eight AAC blocks placed within the beam which was the maximum possible amount of blocks based on the gap size between each blocks to ensure smooth concrete flow without any restriction during pouring. The flexural cracks started to 


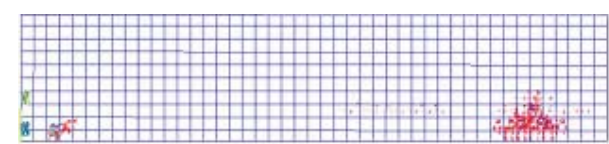

$32.2 \mathrm{kN}$

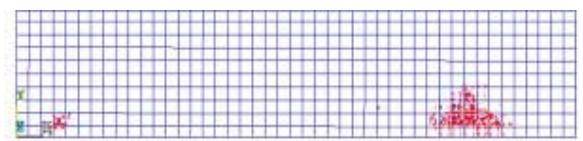

$32.9 \mathrm{kN}$

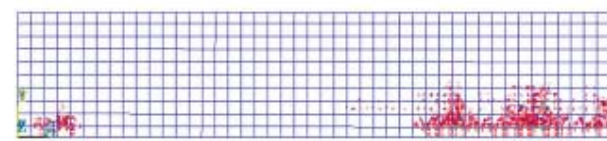

$47.7 \mathrm{kN}$

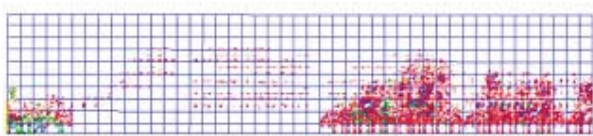

$64.2 \mathrm{kN}$

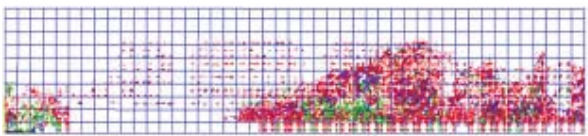

$68.5 \mathrm{kN}$

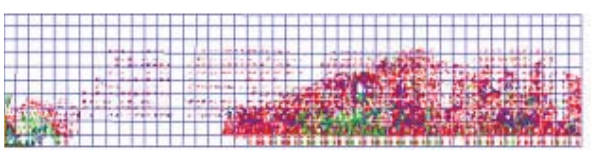

\section{$76.8 \mathrm{kN}$}

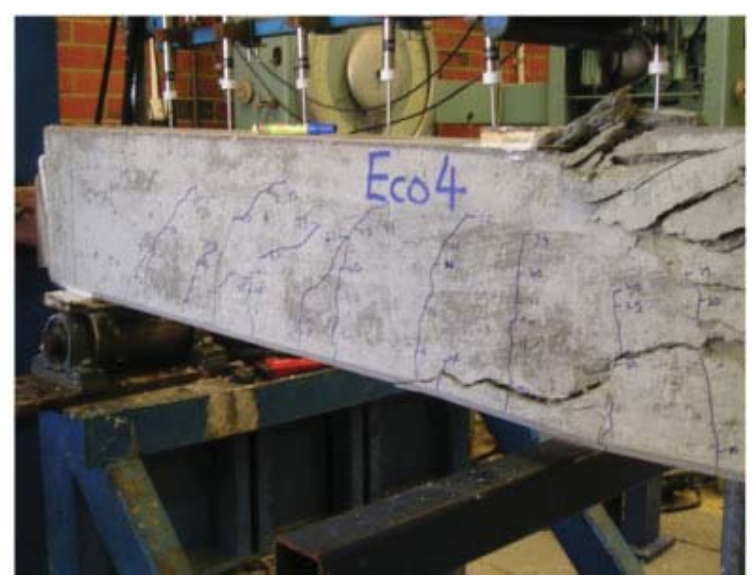

Figure 4. Crack propagation of LB1F.

occur at $32.2 \mathrm{kN}$. Figure 2 shows the crack pattern up to $76.8 \mathrm{kN}$ load level. It is clear that the ANSYS model for LB1F shows more cracks compared to the SB1S. The crack of AAC blocks is noticeable in this model which related to the brittle failure in the actual beam.

\subsection{Beam with half amount of AAC blocks (LB2F)}

This beam contains half amount of AAC blocks compared to LBF1. In this case, the flexural crack started to appear at the load level of $32.9 \mathrm{kN}$. The increasing load caused the crack propagation in the beam. Figure 5 shows the crack pattern of this beam up to $78.6 \mathrm{kN}$.

The first flexural crack occurs on the solid and the LSRC beams were almost at the same load level

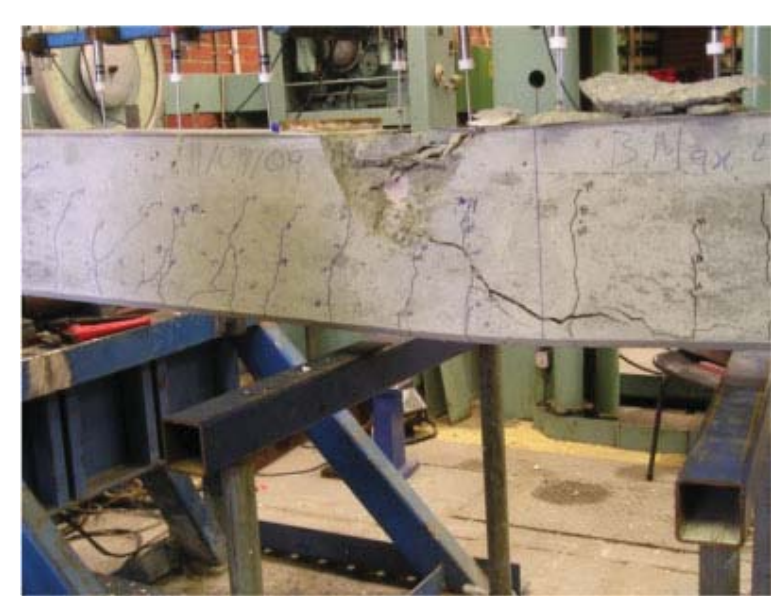

Figure 5. Crack propagation of LB2F.

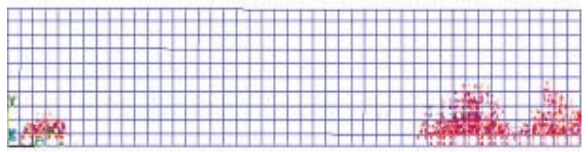

$49.9 \mathrm{kN}$

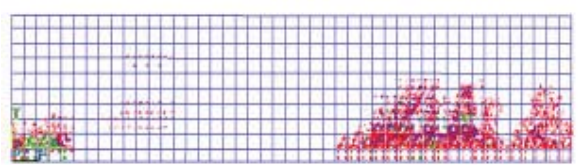

$66.1 \mathrm{kN}$

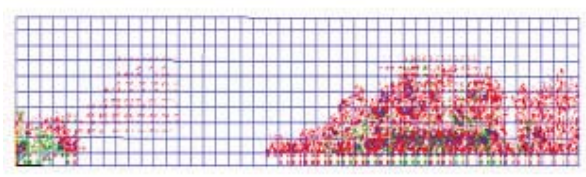

$78.6 \mathrm{kN}$

$(32 \mathrm{kN})$. This finding is just as expected. Before the first crack, the LSRC beams behave the same as the solid one. The crack patterns of these three beams are almost similar. The only different is, the LSRC beams have more cracks compared to the equivalent solid beam due to the crack which also appear in the AAC blocks. The noticeable cracks of the AAC blocks in ANSYS model correlated to the brittle failure in the LSRC beams. The crushing related crack at the top of the beam could not be observed because the crushing capability of ANSYS was turned off.

\section{CONCLUSION}

The experimental results of the flexural and shear tests of solid beams and the developed numerical model of LSRC beams are presented. Crack propagation of 
the beams are closely monitored and the experimental results are compared with the results from FEM analysis.

Based on the results, the crack propagation from ANSYS model compares well with the results from the experiment. ANSYS could predict the similar behaviour of crack propagation in each beam specimen. The crack in AAC block correlated to the brittle failure of the sandwich beams. The benefit of this investigation is that the developed FEM model can be used to analyse similar beam sections with different structural configurations and loading parameters to gain more insights of the behaviour of LSRC members.

\section{REFERENCES}

ANSYS Theory Reference, version 12.1, Swanson Analysis System, available at Curtin University, 2010.

Bangash, M.Y.H., Concrete and Concrete Structures: Numerical Modeling and Applications, Elsevier Science Publishers Ltd, London, 1989.

Barbosa, A.F., Ribeiro ,G.O., Analysis of Reinforced Concrete Structures Using ANSYS Nonlinear Concrete Model, Computational Mechanics, pp. 1-7, 1998.
Büyükkaragöz, A., Finite Element Analysis of the Beam Strengthened with Prefabricated Reinforced Concrete Plate, Scientific Research and Essay, 5(6), 533-544, 2010.

Dahmani, L., Khennane, A., Kaci, S., Crack Identification in Reinforced Concrete Beams Using ANSYS Software, Strength of Material, 42( 2), 2010.

Desayi, P and Krishnan, S., Equation for the Stress-Strain Curve of Concrete, Journal of American Concrete Institute, 61, 345-350, 1964.

Gere, J.M. and Timoshenko, S.P., Mechanics of Materials, PWS Publishing Company, Boston Massachusetts, 1997

Ibrahim, AM., Mubarak, HM., Finite Element Modeling of Continuous Reinforced Concrete Beam with External Pre-stressed, European Journal of Scientific Research, 30 (1), 177-186, 2009.

Kachlakef, D., Miller, T, Yim, S., Chansawat, K., and Potisuk, T., FE Modeling of Reinforced Concrete Structures Strengthened with FRP Laminates, Final Report SPR 316. Oregon State University, 2001.

Padmarajaiah, S.K., Ramaswamy, A., A Finite Element Assessment of Flexural Strength of Prestressed Concrete Beam with Fiber Reinforcement, Cement and Concrete Composites, 24, 229-241, May 2001.

Vimonsatit, V., Wahyuni, A.S., Mazlan, M.A., and Nikraz, H., Use of Lightweight Concrete as Infill of Reinforced Concrete Sections, Proceedings, ACMSM 21, December 7-10, 2010. 